\title{
DETERMINATION OF DEFENCE CAPABILITY REQUIREMENTS
}

\author{
Dejan S. Stojković, Milan S. Kankaraš and Vlada M. Mitić \\ Ministry of Defence of the Republic of Serbia, \\ Defence Policy Sector, Strategic Planning Department
}

A capability-based planning approach provides defence system with adequate response in facing uncertainty, economic constraints and risks. Determination of required defence capabilities is the most important and complex phase in capability-based planning process. The result of this phase is the list of required capabilities of the defence system.

The paper presents method of determination of defence capability requirements and describes practical tools for the identification and the description of required defence capabilities. The capability requirements are identified by perceiving relationships among operational objectives, effects tasks. The capability requirement description contains standards and conditions that clarify necessary capability.

Key words: defence, planning, capability

\section{Introduction}

The modern security environment is very complex, unpredictable and dynamic. In order to provide necessary security to society defence systems ought to possess appropriate capabilities and forces that would enable adequate response to security challenges and threats.

In most countries defence capabilities development is facing resource constraints that limit the achievement of required capabilities. Because of that, through of the process of defence planning it is necessary to establish the balance between needs and opportunities.

There are many defence planning approaches. Each of them has advantages and disadvantages and defence planners try to find the appropriate combination that would enable the achievement of planning goals and objectives.

Capability based planning is the modern planning approach that allows dealing with uncertainty in security environment and resource constraints. However, capability based planning requires structured procedures and specific tools that would enable perceiving all necessary elements and factors within complexity of the process.

The full understanding of the relationships among different entities is necessity for appropriate capability based planning. The linkages among operational objectives, effects and tasks have specific importance.

\footnotetext{
* vlada.mitic@mod.gov.rs
} 
Determination of required defence capabilities is one of the most complex stages in capability based planning. The application of the sophisticated tools enables the identification of relations among different entities and the determination of required capabilities and their elements. The results of this phase have a direct influence on the outcome of the planning process.

\section{The overview of capability-based planning}

Defence planning is a specific planning discipline which purpose is to ensure that a nation has the necessary capabilities and forces to protect national security, interests and values. That is a complex interdisciplinary process that involves many activities which are mutually dependent.

Defence planning is the key phase of defence management process that ought to provide conditions for effective accomplishment of defence missions and tasks, appropriate development of defence capabilities and efficient usage of defence resources. The main outputs from defence planning process are defence goals and objectives as well as ways for achieving them. Defence planning includes the development of a complete set of plans and sub-plans which are necessary for coordination and integration of different activities.

Defence planning usually involves various branches. In the case of the Republic of Serbia defence planning involves preparation of strategic-doctrinal documents, defence development planning and force usage planning. A similar approach is applied in many other countries but there are different examples as well. ${ }^{1}$

Defence development planning is very important part of defence planning. ${ }^{2}$ That is a process of setting the defence development objectives and identifying ways and means to accomplish them. Results of this process are defence development planning documents. ${ }^{3}$

There are many different approaches in defence development planning that are shaped for usage in the defence field or taken from non-government sector. The most often approaches are: top-down planning, resource-constrained planning, technological optimism, risk avoidance, incremental planning, historical extension, capability-based planning, scenario-based planning and threat-based planning [1].

Each method has own advantages and disadvantages. In practice, it is unusual to apply just one approach of defence development planning. In the real world, it is common for defence development planning to combine several of these approaches.

Capability based planning is dominant approach in defence development planning for last two decades. This approach is designed by the RAND Corporation at the beginning

\footnotetext{
${ }^{1}$ Defence planning is very often related to defence capabilities development and does not deal with force usage issues.

${ }^{2}$ Defence development is the sum of qualitative and quantitative changes that the result is more effective and more efficient defence system.

${ }^{3}$ The basic defence development planning documents in the Republic of Serbia are: Long-term Defence Development Plan of the Republic of Serbia, Strategic Defence Review of the Republic of Serbia and Mid-term Defence Development Plan and Program.
} 
of XXI century in order to enable appropriate response in facing uncertainty, economic constraints and risks [2]. The practical application of this approach began in the United States, and later on the approach was accepted by Canada, the UK, Australia, New Zealand and the growing number of NATO member states. The generic model of capability-based planning process is shown on Figure 1.

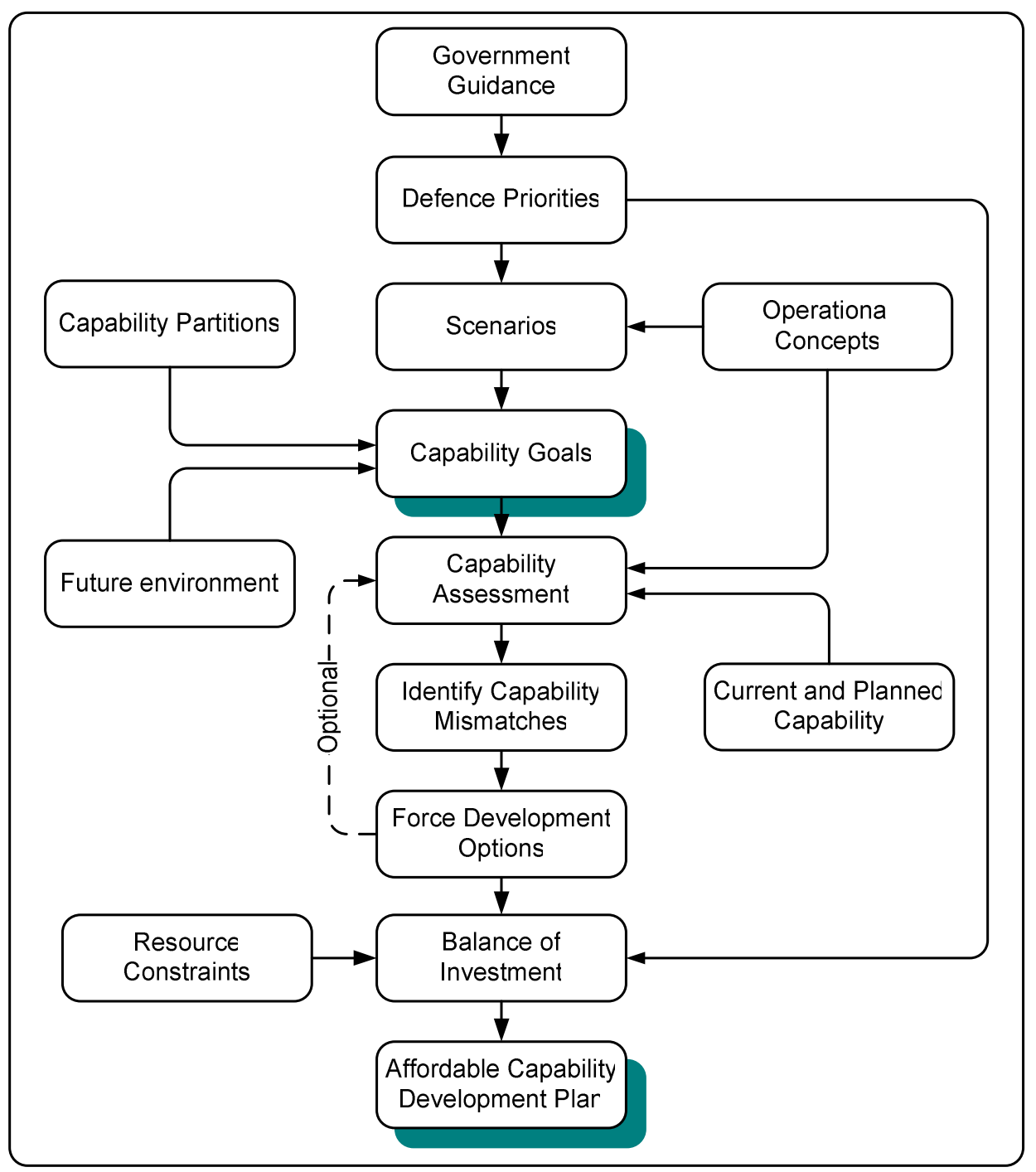

Figure 1 - Generic Process Chart of Capability-Based Planning [3] 
The generic model of capability based planning served as a base for designing many other models. Those models are mainly the result of modifications of generic model and attempt to adjust the generic model for implementation in certain circumstances.

One of the comprehensive models of capability based planning applied in defence development planning process in the Republic of Serbia is shown on Figure 2 [4]. The major stages of presented planning model will be briefly described in the following text.

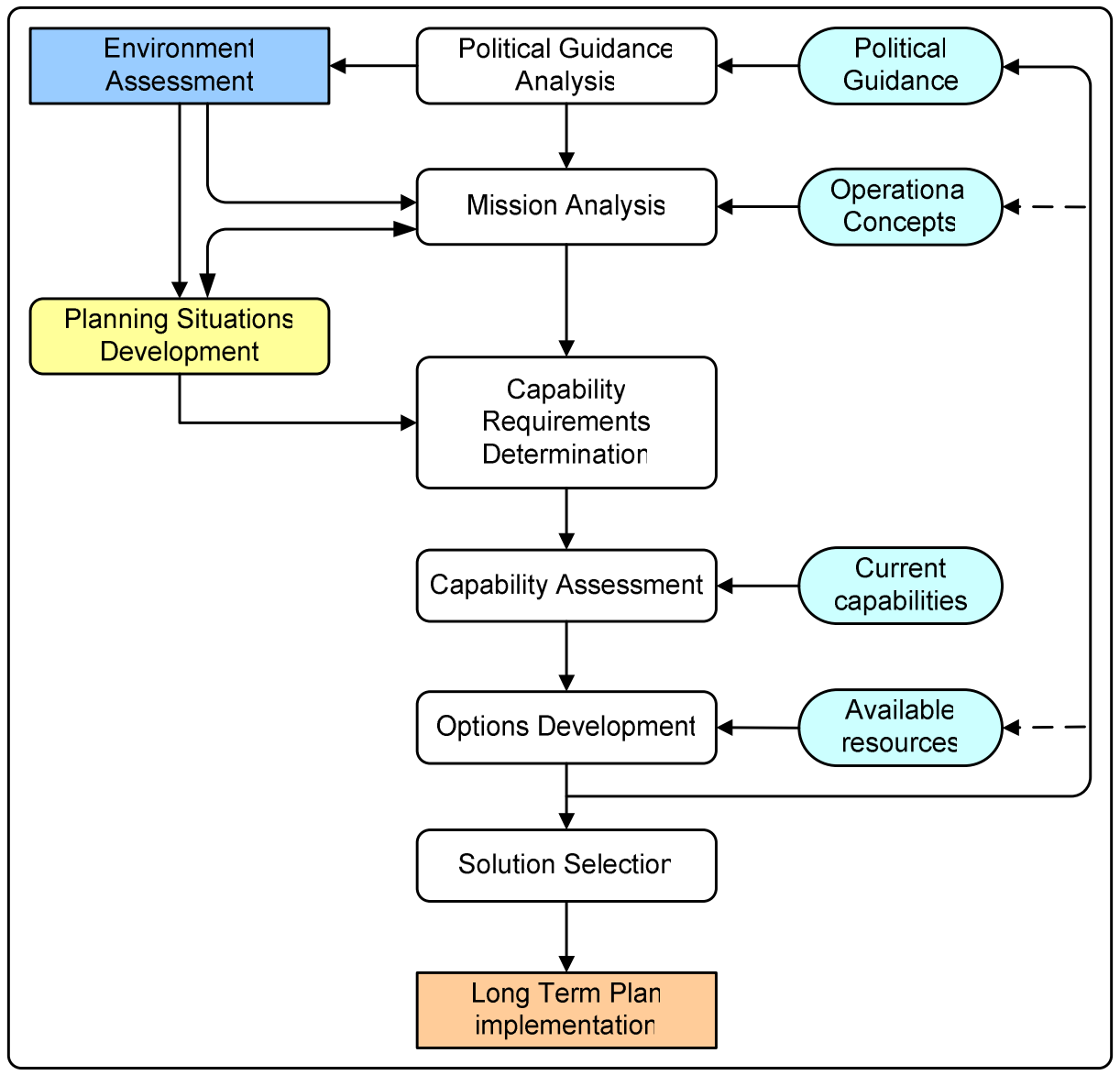

Figure 2 - Model of capability based development planning process [4]

The first stage is Political Guidance Analysis. Political Guidance Analysis clarifies defence policy, level of ambition, limitations and some others issues which lead to defence mission and tasks identification as well as defence priorities determination. Major inputs in this stage are: national interests and objectives, role and the importance of allies, friendly nations and international organizations etc. 
The Environment Assessment is the second stage in the development planning process. This stage includes gathering and analysing necessary information, identification of security challenges and threats as well as designing a proper number of strategic situations.

The third stage is Mission Analysis. The function of this stage is to identify what should be done in order to achieve determined operational goals and objectives considering defence missions and operational concepts as inputs. The final output from this stage is multi-level task structure.

Scenario development is the fourth stage of the capability based planning process. In this stage a suitable number of scenarios are designed for each of the previously defined strategic situations. ${ }^{4}$ The developed scenarios should be related to all types of military operations that are determined in the third stage.

Probably the hardest part of the capability-based planning process is Capability Requirements Determination stage. The aim of this stage is to identify defence capabilities that are required to achieve desired operational goals and objectives. Determination of capability requirements should take into consideration standards and conditions for operational tasks accomplishment.

Capability Assessment is sixth stage in the process. The purpose of this stage is to assess the capability gap between current and required capabilities.

Seventh stage in capability based planning process is Options Development. Options should provide ways for bridging previously identified capability gap. The options should be based on resource constraints and take into consideration both material and nonmaterial approaches.

Solution Selection is the last stage of capability-based planning process. The result of this stage is the option which provides the best balance between capability requirements and resource affordability. The specific output of the stage is risk specifications which are related to uncovered capability requirements.

\section{Relationships among different entities in capability based planning}

Analysis of many definitions pointed out that capability is the ability and capacity to perform the tasks and achieve the desired effects under specific standards and conditions in order to accomplish the defined objectives [5]. Proper understanding of the relationship among different entities is necessity for full and appropriate implementation of the capability based planning. The reason for that is encompassed in the definition of the term capability.

The definition indicates specific interdependence among objectives, effects, tasks and capabilities. Objectives represent desired results that are accomplished by achieving the suitable effects while effects are achieved through performing specific tasks. Defence

\footnotetext{
${ }^{4}$ There are two main types of scenarios: developmental and situational [5]. The developmental scenario takes the current situation as a starting point, determining how the situation will occur in the future. Situational scenario describes a specific situation within a certain period of time (hours, days or months of operation).
} 
capabilities enable execution of tasks and achievement of effects in order to fulfil established objectives. The relationships among objectives, effects, tasks and capabilities are shown on Figure 3.

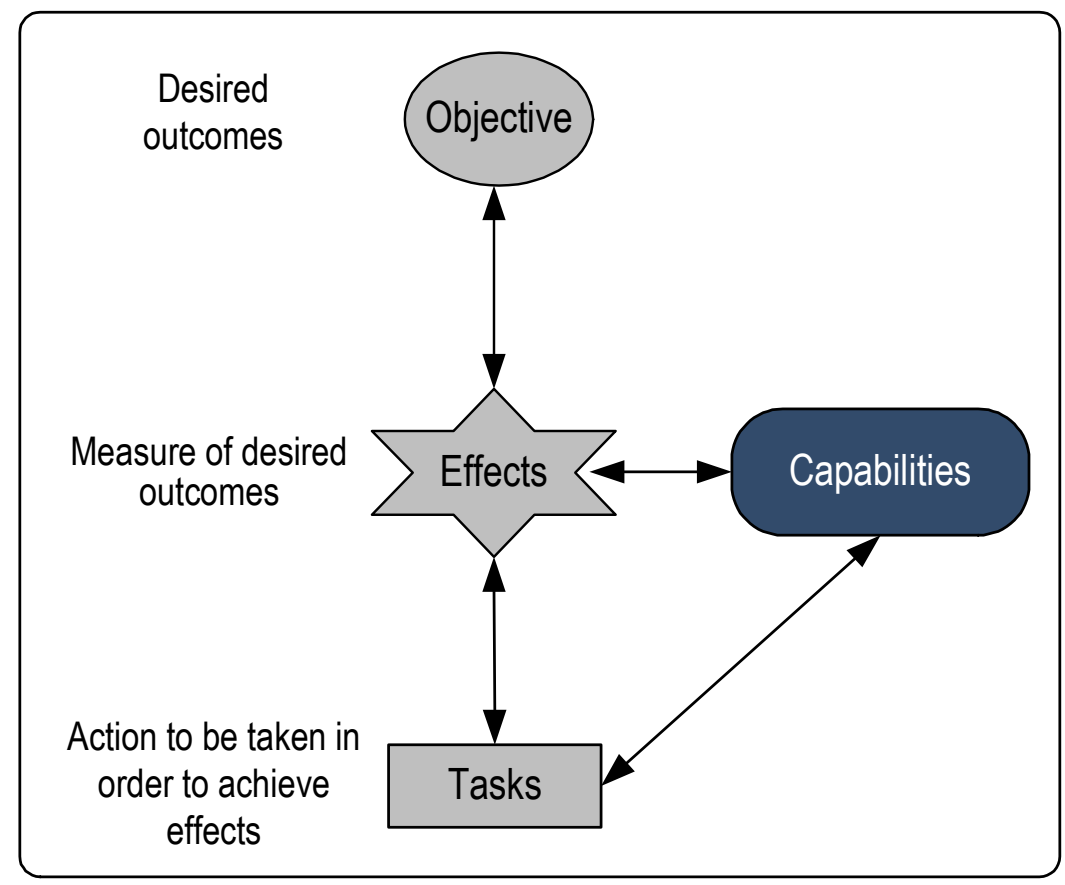

Figure 3 - Relationships among objectives, effects, tasks and capabilities

In order to fully understand interdependencies among objectives, effects, tasks and capabilities it is useful to perceive relationships among them from operational perspective as well. In this sense, the starting points are general and specific operational objectives. General objectives are related to a desired operational end state and achieved by accomplishing specific objectives.

Operational effects have a dual character and can be observed from planning and execution perspective. ${ }^{5}$ In the planning process, required effects come out from objectives, and lead to tasks that are necessary to be executed. The execution of required tasks produces the desired effects that may also generate other effects. Desired effects that are directly produced by task execution are direct or first order effects. Other effects which are result of existence of direct effects are considered as indirect and can be marked as second, third etc. order effects. Dual nature of the effects is shown on Figure 4. [6]

\footnotetext{
${ }^{5}$ An effect is the physical condition and/or behaviour of the system that has arisen as a result of combat and non-combat operations and depends on a certain situation.
} 


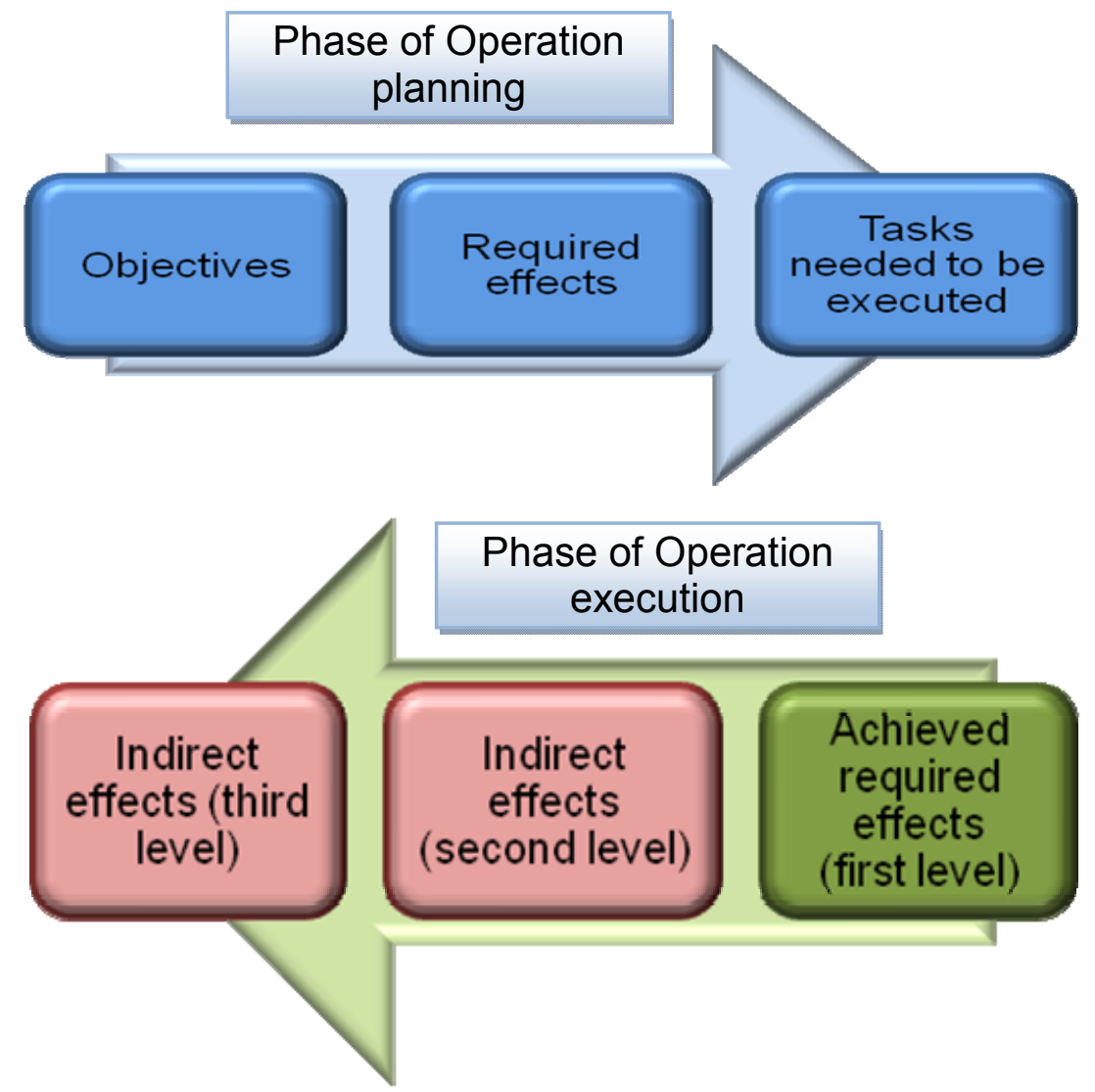

Figure 4 - Dual nature of effect (adopted from [6]

According to Paul Davis, there are physical and behavioural effects. Physical effects may include: equipment or systems damaging, processes disrupting and people killing. On the other hand, behavioural effects are related to demoralization and thereby reduction the fighting capabilities of military forces (or population), confusion of commanders, influencing decision making etc. [7].

Effects are considered in two categories: decisive and auxiliary. Decisive effects are achieved by actions on critical enemy capabilities in order to meet operational and strategic objectives, and auxiliary effects create the conditions to achieve decisive effects.

Planned operational effects can have different nature and characters which depend on specific operational needs (prevent, destroy, restrict and so on). For planning purpose, it is very useful to describe each specific effect and establish precise standards which should be met in order to achieve desired effects. Sample descriptions of operational effects and standards for achieving the effects are given in Table 1. 
Table 1 - The example of an effect description [8]

\begin{tabular}{|c|c|c|c|}
\hline \multirow{2}{*}{ Effect } & \multirow{2}{*}{ Description } & \multicolumn{2}{|r|}{ Standard } \\
\hline & & Measure & Criterion \\
\hline \multirow{2}{*}{ Neutralize } & \multirow{2}{*}{$\begin{array}{l}\text { Rendering enemy personnel or } \\
\text { materiel incapable of interfering in } \\
\text { particular operations }\end{array}$} & $\%$ & $\begin{array}{l}x \% \text { enemy personal and/or } \\
\text { weapons and military } \\
\text { equipment are incapable of } \\
\text { interfering in a particular } \\
\text { operation }\end{array}$ \\
\hline & & $\begin{array}{l}\text { hours/day } \\
\text { s }\end{array}$ & $\begin{array}{l}\text { Enemy personal and/or } \\
\text { weapons and military } \\
\text { equipment are incapable of } \\
\text { interfering in a particular } \\
\text { operation for } y \text { days. }\end{array}$ \\
\hline \multirow{2}{*}{ Defeat } & \multirow{2}{*}{$\begin{array}{l}\text { Enemy forces has temporarily or } \\
\text { permanently lose the physical } \\
\text { means or will to fight }\end{array}$} & $\%$ & $\begin{array}{l}\text { Causing the opponents up to } z \\
\% \text { of losses in the personnel } \\
\text { and/or weapons and military } \\
\text { equipment }\end{array}$ \\
\hline & & $\%$ & $\begin{array}{l}\text { Causing the opponent up to } q \\
\% \text { of personnel lose will to fight }\end{array}$ \\
\hline Destroy & $\begin{array}{l}\text { Physically render an enemy force } \\
\text { combat-ineffective until it is } \\
\text { reconstituted. }\end{array}$ & $\%$ & $\begin{array}{l}\text { Causing the opponents up to } w \\
\% \text { of losses in the personnel } \\
\text { and/or weapons and military } \\
\text { equipment }\end{array}$ \\
\hline
\end{tabular}

The description of operational effects and standards for their achievement is supposed to help defence planners with identifying the tasks which should be executed. Identified operational tasks imply capabilities which are necessary for desired effects production and operational objectives achievement.

\section{Method of determination of defence capability requirements}

One of the most complex stages in capability based planning process is determination of required defence capabilities. The results of this stage directly affect the outcome of the whole planning process. In that regard, the determination of required defence capabilities must be approached systematically and thoroughly in order to eliminate any possible mistakes. 
The basic mistake that is often made in this process is to perceive operational capabilities as forces, resources or structures. Accordingly, defence planners have to keep in mind that the capability represents the ability and capacity to perform the tasks and achieve the desired effects. They must avoid thinking about forces and structures when they deal with capability based planning.

Keeping in mind the definition of capability, the first step in the required defence capabilities determination stage is related to objectives, tasks and effects analysis. Objectives, effects and tasks are analyzed at the strategic, operational and tactical level and for each specific planning scenario. Tasks at a higher level in principle are transformed into objectives at a lower level (Figure 5). Operational objectives can be achieved by reaching one or more effects by execute multiple tasks. ${ }^{6}$

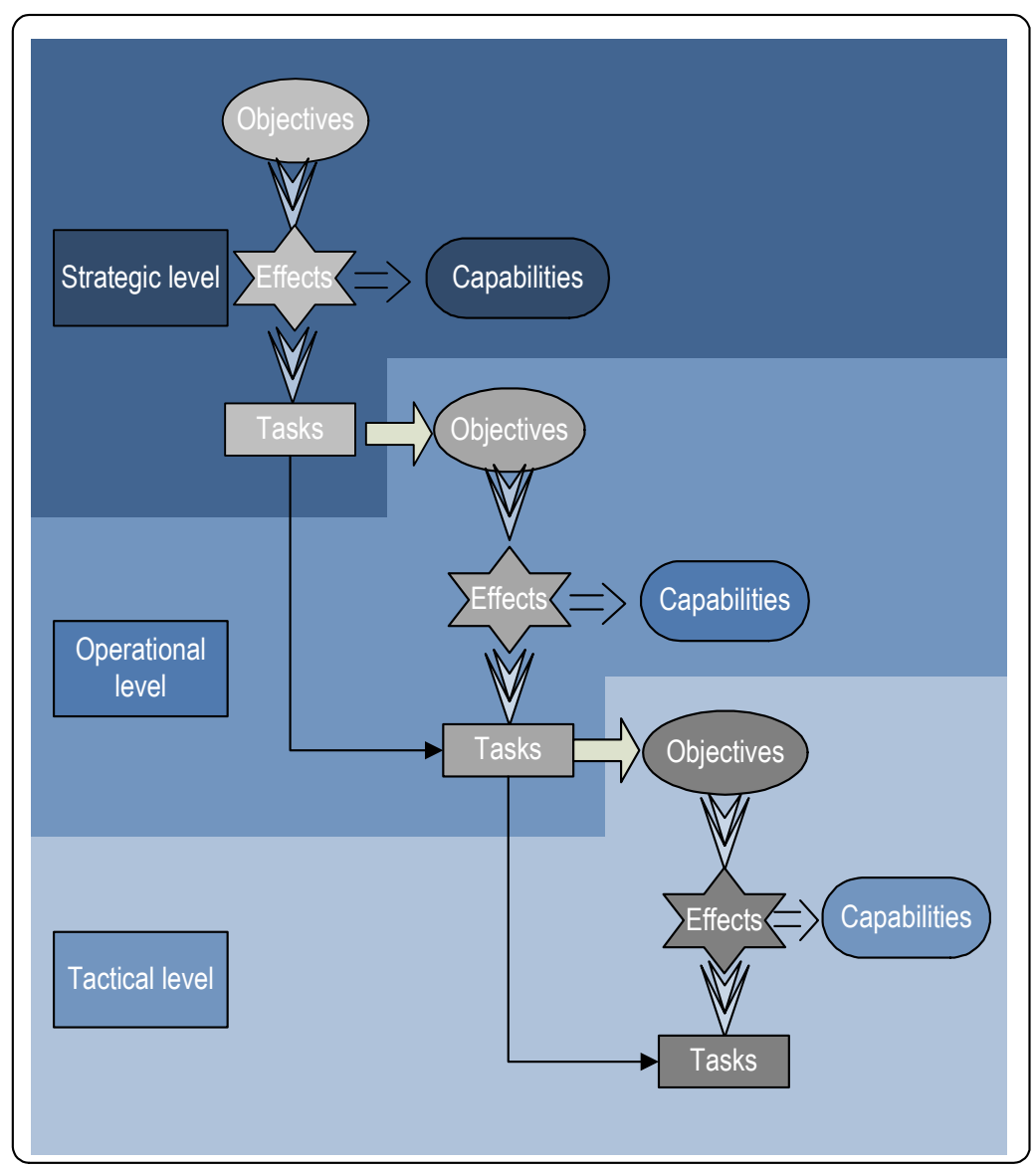

Figure 5 - The objectives, effects and tasks analysis

\footnotetext{
${ }^{6}$ The results from task decomposition process can be used for updating the universal task lists of defence forces.
} 
The appropriate tool for recording of the results of objectives, effects and tasks analysis is a specific pattern that is named Scenario Task List (Table 2). Tasks ought to be generally grouped into the so-called combat (operational) functions: command, manoeuvre, intelligence (information), fire-action, force protection and sustainability of forces.

Table 2 - Scenario Task List

\begin{tabular}{|c|c|c|c|}
\hline Objective & Effect & Task & $\begin{array}{c}\text { Is it in Universal } \\
\text { Task List } \\
\text { (YES/NO) }\end{array}$ \\
\hline \multirow{20}{*}{$\begin{array}{c}\text { Strategic objective } \\
\text { SO-1 }\end{array}$} & \multirow{18}{*}{$\begin{array}{l}\text { Strategic effect } \\
\text { SE-1 }\end{array}$} & Command and Control & \\
\hline & & Task C-1 & \\
\hline & & Task C-2... & \\
\hline & & Manoeuvre & \\
\hline & & Task M-1 & \\
\hline & & Task M-2... & \\
\hline & & Intelligence (information) & \\
\hline & & Task I-1 & \\
\hline & & Task I-2 ... & \\
\hline & & Fire- action & \\
\hline & & Task F-1 & \\
\hline & & Task F-2 ... & \\
\hline & & Force protection & \\
\hline & & Task P-1 & \\
\hline & & Task P-1... & \\
\hline & & Sustainability of forces & \\
\hline & & Task S-1 & \\
\hline & & Task S-2 ... & \\
\hline & $\begin{array}{l}\text { Strategic effect } \\
\text { SE-2 }\end{array}$ & $\cdots$ & \\
\hline & $\begin{array}{c}\text {... Strategic effect } \\
\text { SE-n }\end{array}$ & $\cdots$ & \\
\hline
\end{tabular}

The next part of determination of required defence capabilities is focused to identifying necessary capabilities. This stage of the process involves linking effects and decomposed tasks with defence capabilities required for their execution. Required capability comes from effects that must be achieved, while operational capability elements are correlated with tasks needed to be performed (Figure 6). Tasks, which are previously grouped according to combat (operational) functions, are transformed into operational capability elements. ${ }^{7}$ The final result of the process is a list of required defence capabilities by levels (strategic, operational and tactical).

\footnotetext{
${ }^{7}$ Each capability consists of capability elements. Some elements produce direct effect while some are preconditions for effect production. The compound of capability elements represents the certain capability.
} 


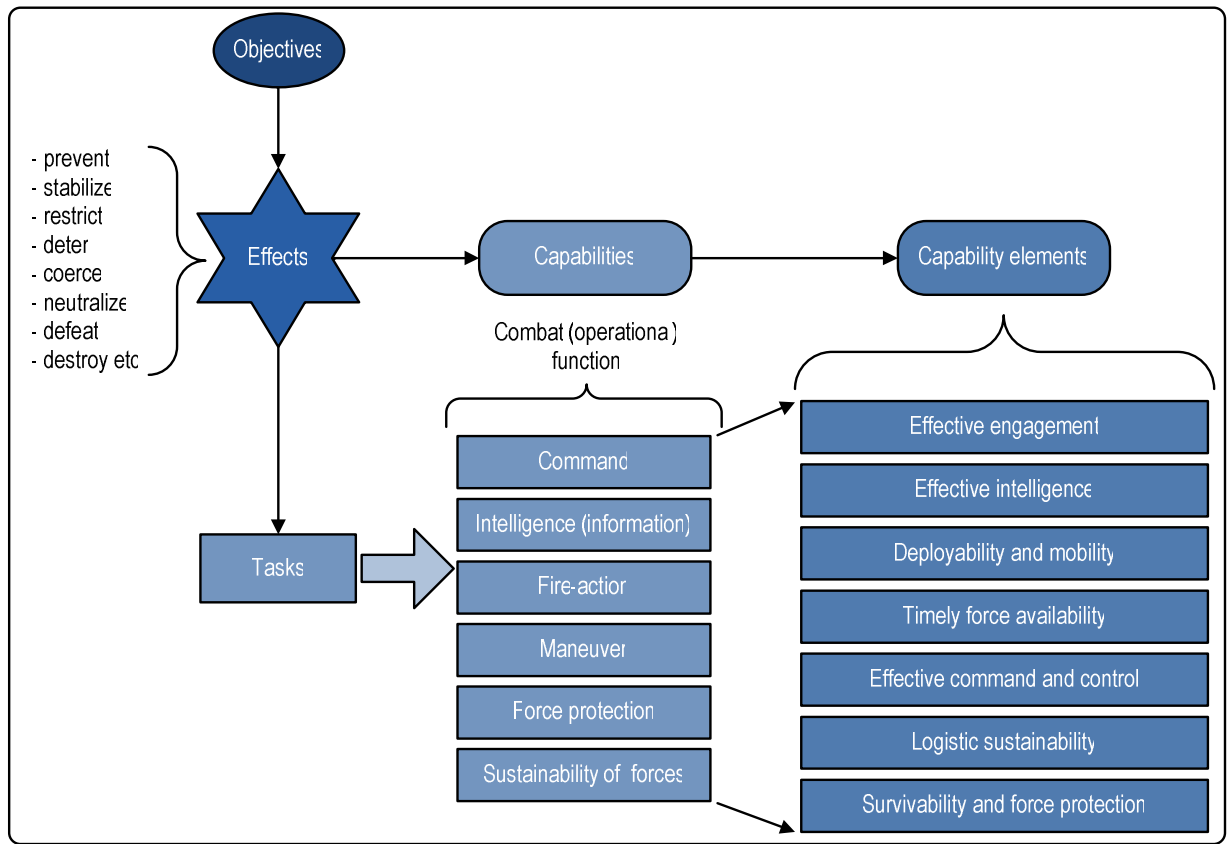

Figure 6 - Identification of required capability

Each of the identified capability should be described. The description should contain general characteristics of specific capability, elements that it contains, as well as specific standards and conditions. A suitable tool for capability description is so-called Capability profile (Table 3).

Table 3 - Capability profile

\begin{tabular}{|c|c|c|}
\hline CAPABILITY NAME: & \multicolumn{2}{|c|}{ Preventing enemy to take control over strategic objects } \\
\hline CAPABILITY CODE: & \multicolumn{2}{|l|}{ E001 } \\
\hline CAPABILITY DESCRIPTION: & \multicolumn{2}{|c|}{$\begin{array}{l}\text { Prevent enemy to take control over strategic object S1, through } \\
\text { strategic direction SD1 in all weather conditions during } 20 \text { days }\end{array}$} \\
\hline \multirow{2}{*}{ Capability element } & \multicolumn{2}{|c|}{ Standards } \\
\hline & Measure & Criteria \\
\hline \multirow{3}{*}{ Effective engagement } & $\%$ & destroy $30 \%$ of enemy tanks \\
\hline & $\%$ & destroy $20 \%$ of enemy solder \\
\hline & $\ldots$ & $\ldots$ \\
\hline Effective intelligence & $\ldots$ & $\ldots$ \\
\hline \multirow{2}{*}{ Deployability and mobility } & $\mathrm{km}$ & $200 \mathrm{~km}$ movement in 7 hours \\
\hline & $\ldots$ & $\ldots$ \\
\hline
\end{tabular}


Determination of Defence Capability Requirements

\begin{tabular}{|l|c|c|}
\hline \multirow{2}{*}{ Capability element } & \multicolumn{2}{|c|}{ Standards } \\
\cline { 2 - 3 } & Measure & Criteria \\
\hline Timely force availability & $\ldots$ & $\ldots$ \\
\hline $\begin{array}{l}\text { Effective command and } \\
\text { control }\end{array}$ & $\ldots$ & $\ldots$ \\
\hline \multirow{4}{*}{ Logistic sustainability } & days & food preparation autonomy for 20 days \\
\cline { 2 - 3 } & days & munitions supply autonomy for 10 days \\
\cline { 2 - 3 } & $\ldots$ & $\ldots$ \\
\hline \multirow{2}{*}{$\begin{array}{l}\text { Survivability and force } \\
\text { protection }\end{array}$} & level of protection & Solder protection level 3 \\
\cline { 2 - 3 } & level of protection & Armoured platform protection level 5 \\
\cline { 2 - 3 } & $\ldots$ & $\ldots$ \\
\hline
\end{tabular}

The description of capability requirements, which are elaborated through capability elements and specific standards and conditions, establishes the foundation for measures and actions within capability inputs that should be performed in order to develop the required capability. ${ }^{8}$

The determination of capability requirements is the input into the next stage of capability based planning which is aimed to identification of the current and future capability gaps. In order to overcome gaps many options should be developed and the selected option ought to be described within the affordable capability development plan.

\section{Conclusion}

The capability based planning is a modern defence planning approach that enables identification of necessary capabilities in accordance with defence policy and security challenges and threats. Identified capability requirements are a base for the planning of defence system development but it is necessary to establish the balance between defence needs and state and society opportunities.

The determination of capability requirements is one of the most complex stages in the process of capability-based planning. The sense of this stage is to identify capabilities needed to perform tasks and achieve desired operational effects, under specific standards and conditions.

There is a directed link among required capabilities, tasks, operational effects and objectives. Capabilities enable performing of tasks and achievement of operational effects in order to accomplish operational objectives.

In order to identify capability requirements it is fundamental to analyse operational objectives, effects and tasks, in accordance with chosen planning scenarios. The analysis allows comprehensive understanding of interdependencies among objectives, effects,

\footnotetext{
${ }^{8}$ Capability inputs are: doctrine, organization, training, material, personnel, leadership, facilities and interoperability.
} 
tasks. The desired operational effects are related to capabilities and decomposed tasks are linked with capability elements.

The determination of capability requirements demands the application of specific tools and instruments. Scenario Task List and Capability profile are simple but practically proven tools that can be very helpful in the planning process. The knowledge and the experience of planners are implied.

The presented method is primary intended for using in the defence sector, but it can be applied in many similar organizations (police, security agencies etc.). In that case, the method should be slightly adjusted.

\section{References}

[1] RTO/NATO, Handbook on Long Term Defence Planning, RTO-TR-069, 2003.

[2] Vencel, C. L., \& Matthews, D.: A System Analysis of the DCPG Capability Domain Architecture - Part One: Characteristics of Idealized Domain and Domain Set, DSTO Technical Report, Edinburgh, 2002.

[3] Guide to Capability-Based Planning, The Technical Cooperation Program (www.acq.osd.mil/ttcp/reference/docs/JSA-TP-3-CBP-Paper-Final.doc) - accessed: 10. February 2016.

[4] Stojkovic, D., \& Dahl, R. B.: Methodology for long term defence planning, Norwegian Defence Research Establishment (FFI), Lilestrom, 2007.

[5] Kovač, M., \& Stojković, D.: Strategijsko planiranje odbrane, Vojnoizdavački zavod, Belgrade, 2009.

[6] Mann, E. C., Endersby, G., \& Searle, T. R.: Thinking Effects - Effects-Based Methodology for Joint Operations, Air University Press, Alabama, 2002.

[7] Davis, P.: Analytic Architecture for Capabilities-Based Planning, Mission System Analysis, and Transformation, RAND MR-1513-OSD, 2002.

[8] FM 3-90 Tactics. Headquarters Department of the Army. United States of America. (http://www.bits.de/NRANEU/others/amd-us-archive/fm3-90(01).pdf) - accessed: 20. July 2016.

[9] An Introduction to Joint Operations on and from the Sea. (2012). CJOS Handbook 2012/1. 2006.

[10] Dictionary of Business and Management - fourth edition, Oxford University Press, Oxford,

[11] Kovač, M., Dulanović, Ž., \& Stojković, D.: Određivanje efikasnosti vojnoorganizacionih sistema, Vojnoizdavački zavod, Belgrade, 2006.

[12] Taylor, B.: Guide to Capability-Based Planning in Analytical Support to Defence Transformation. Meeting proceedings RTO-MP-SAS-055, Paper 8 (pp. 8-1-8-14), Neuillusur-Seine, France, 2005.

[13] Walker, R.: Towards Defence Capability Management: A Discussion Paper, 2002.

[14] Spiegeleire, S: Ten trends in capability planning for defence and security, The Rusi Journal, October/November 2011, vol 156, No. 5, pp. 20-28. 